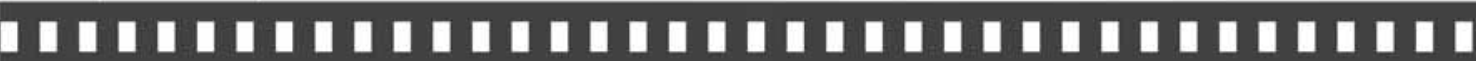

\section{Vidas Secas: o Sertão nas Fotografías de Evandro Teixeira}

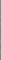

CarlaAdelina CraveiroSilva

\author{
Marcelo Eduardo Leite
}

Artigo recebido em: 04/02/2014

Artigo aprovado em: 24/10/2014 


\title{
Vidas Secas: 0 Sertão nas Fotografias de Evandro Teixeira
}

Barren lives: hinterland in Evandro Teixeira's photography

\author{
CarlaAdelina Craveiro Silva* \\ MarceloEduardo Leite ${ }^{* *}$
}

\begin{abstract}
Resumo: Nosso objetivo é trazer questões sobre a relação entre a narrativa fotográfica e a narrativa literária que compartilham a escolha do ambiente nordestino como espaço de abordagem. Deste modo, o ensaio realizado por Evandro Teixeira para ser publicado junto a uma reedição do livro "Vidas Secas", de Graciliano Ramos, faz-se o nosso objeto de análise. Buscamos, ainda, melhor compreender a maneira como as referências pessoais do fotógrafo e a trama constituída no enredo literário emergem na representação fotográfica.
\end{abstract}

Palavras-chave: Narrativa fotográfica. Evandro Teixeira. Sertão.

\begin{abstract}
Our aim is to raise questions about the relationship between the photographic narrative and the literary narrative that have in common the choice for the northeastern ambience. Therefore, the photographic essay made by Evandro Teixeira to be included in the reissue of the book "Barren Lives", of Graciliano Ramos, became our object of analysis. We also search for a better understanding about the manner in which the personal references of the photographer and the thread constituted in the literary plot emerge in photographic representation.
\end{abstract}

Keywords: Photographic narrative. Evandro Teixeira. Hinterland.

* Mestranda em Comunicação pela UNB. Bacharel em Comunicação Social - Jornalismo pela UFC. E-mail: carla.a.craveiro@gmail.com

** Professor Adjunto III da Universidade Federal do Cariri, Juazeiro do Norte - CE. Doutor em Multimeios pela UNICAMP. Mestre em Sociologia e bacharel em Ciências Sociais pela UNESP. E-mail: marceloeduardoleite@ gmail.com 


\section{Introdução}

No âmbito da fotografia brasileira, a representação do Nordeste surge pautada na recorrência a alguns referenciais historicamente constituídos, e a literatura está entre eles. As reflexões aqui apresentadas fazem parte do nosso esforço em compreender algumas formas que tomam essa representação. A proposta parte da análise de alguns trabalhos realizados na segunda metade do século XX e na primeira década do século XXI, os quais, guardadas as peculiaridades, apresentam pontos de convergência nas opções de temas e de elementos relacionados à região com os quais tecem diálogos. Neste trabalho, traremos algumas questões relacionadas ao ensaio do fotógrafo Evandro Teixeira que tem, em Vidas Secas, romance de Graciliano Ramos, o ponto de partida para sua realização. Desta maneira, temos o intuito de lançar luz sobre a relação entre as representações fotográficas acerca do Nordeste e as obras literárias que o elegeram enquanto espaço para os seus enredos.

Os caminhos a serem percorridos ao se ter a fotografia como objeto de análise passam por alguns pontos essenciais. Pensá-la como fruto da articulação entre ações de naturezas diversas implica refletirmos sobre o quão determinantes cada uma delas pode ser para o resultado final. Fotógrafo, câmera e cultura são elementos base para que a produção da imagem se efetive.

A fragmentação temporal/espacial inerente à imagem fotográfica decorre das opções do fotógrafo, que, uma vez inserido em um determinado ambiente, opta por composições e enquadramentos que conferem um novo significado a um aspecto específico, dentre infinitas possibilidades. Para tanto, ele lança mão do seu conhecimento a respeito da técnica e, assim, a construção de seu discurso se dá à medida que a exploração dos recursos da câmera combina-se com suas intencionalidades.

Nos termos de Kossoy (1999, p. 26-27), tal condição determina que o fotógrafo assuma a função de filtro cultural da realidade. Assim, a superfície fotossensível é impressionada com uma construção particular 
que constitui uma representação a partir do real. Esta se faz imbuída de elementos subjetivos oriundos do indivíduo que fotografa, como a sua trajetória pessoal, suas influências estéticas e técnicas e sua relação com a temática e o ambiente abordados.

Para Flusser, "[...] toda fenomenologia do gesto fotográfico deve levar em consideração os obstáculos contra os quais o gesto se choca" (1985, p. 18). O autor argumenta que o ato de fotografar é uma forma de avançar contra as intenções intrínsecas à cultura, buscando dominá-las. Neste sentido, o ambiente no qual tal ato ocorre configura as opções de que o fotógrafo dispõe e adota. Logo, "Decifrar fotografias implicaria, entre outras coisas, o deciframento das condições culturais dribladas" (FLUSSER, 1985, p. 18).

Portanto, para que a análise de imagens fotográficas se constitua, deve-se levar em consideração o percurso que lhes deu condições de existência, atentando para as condições técnicas e estéticas articuladas pelo fotógrafo, além dos objetivos aos quais elas se prestam. O espaço e a maneira como é acessado faz-se um importante fator para a compreensão das características assumidas em um discurso imagético. A partir deste pressuposto, o conhecimento sobre a trajetória do fotógrafo e sobre o contexto no qual as imagens são realizadas traz a possibilidade de uma análise mais aprofundada sobre a problemática em questão.

\section{Nordeste dentro dos Nordestes Imaginados}

Do ponto de vista político-administrativo, a região Nordeste é composta pelos estados da Bahia, Sergipe, Alagoas, Pernambuco, Paraíba, Rio Grande do Norte, Ceará, Piauí e Maranhão" . "No entanto, a história dos estados do Nordeste não revela uma tendência para a unidade regional, sendo marcada por diferenças políticas e econômicas importantes" (CARVALHO, 2006, p. 9), mas, o caráter de heterogeneidade não marca

1 Esta divisão foi oficializada pelo IBGE nos anos 70. 
apenas essas perspectivas. Os domínios físicos e climáticos que compreendem seu território apresentam, também, ampla diversidade de configuração. Tais características nos trazem a percepção de que, quando se fala em Nordeste, nos referimos a um território geográfico que abriga espaços diferenciados, com trajetórias históricas e sociais peculiares.

As condições que delineiam suas fronteiras colaboram para a compreensão dos aspectos físicos que a este espaço estão relacionados. No entanto, conduzem, também, as atribuições valorativas que determinam a caracterização cultural e social com as quais sua população e seu espaço são vinculados, influenciando, desta maneira, as falas ao seu respeito. Para Albuquerque Junior (2006), o conceito de Nordeste como uma região detentora de coesão entre os elementos econômicos, políticos e sociais que culminam na instituição de uma unidade sob vias históricas, culturais e territoriais é recente e firma-se sobre discursos inicialmente forjados em meados da década de 1920.

No âmbito da realização do $1^{\circ}$ Congresso Brasileiro de Regionalismo, em 1926, há indícios que nos permitem identificar certas posturas ideológicas que foram assumidas em alguns setores sociais. Carvalho (2006, p. 4) aponta o Manifesto Regionalista, divulgado por Gilberto Freyre na ocasião do congresso, como um elemento que colabora na definição dos parâmetros de leitura da região Nordeste. Contudo, o autor argumenta que a proposta de Freyre,

[...] passa à margem das divergências políticas na dimensão intraregional, concede ao regionalismo um papel decisivo na preservação da unidade nacional e na compreensão da sociedade brasileira, e defende as tradições culturais regionais em face das influências externas (CARVALHO, 2006, p. 4).

Desta maneira, as ideias de Freyre já sinalizam tendências que influenciariam discursos políticos, artísticos e acadêmicos que se propuseram a tratar dessa região. Nos termos de Silveira (1983, apud CARVALHO, 2006, p. 4-5), o posicionamento legitimado por Freyre é uma das perspectivas que colaboram no sentido de formatar um conceito 
de Nordeste. Estão entre elas, também, a divisão político-administrativa pautada numa visão estadualista das definições de território, as quais marcaram o início do período republicano no Brasil e a via de compreensão elucidada por Celso Furtado, segundo a qual o país abrigaria duas configurações socioeconômicas antagônicas: a desenvolvida e a subdesenvolvida.

Historicamente formatadas, as referências ao Nordeste são conduzidas por e conduzem discursos em diversas áreas. A esfera artística é uma das que tiveram importante papel no processo de construção do universo representativo que diz respeito à região. Neste sentido, é no meio "intelectual" que os valores regionais, o apego às tradições, o evocar das paisagens telúricas, entre outros elementos eleitos para significarem nordestinidade, se estabelecem com força suficiente para a manutenção dessa forma de ver, a qual se faz fonte de inspiração para outras interpretações. Albuquerque Junior defende que as características atribuídas por determinadas produções artísticas à região instauram dizeres generalizantes sobre o conceito de Nordeste, elegendo elementos singulares de um espaço específico para representarem a totalidade. Segundo o autor,

Os romances de Graciliano Ramos e Jorge Amado, da década de trinta, a poesia de João Cabral de Melo Neto, a pintura de caráter social, da década de quarenta, e o Cinema Novo, do final dos anos cinqüenta e início dos anos sessenta, tomarão o Nordeste como o exemplo privilegiado da miséria, da fome, do atraso, do subdesenvolvimento, da alienação do país. Tomando acriticamente o recorte espacial Nordeste, esta produção artística "de esquerda" termina por reforçar uma série de imagens e enunciados ligados à região que emergiram com o discurso da seca, já no final do século passado (ALBUQUERQUE JUNIOR, 2006, p. 192).

Configura-se, portanto, um conjunto de subsídios imagéticos que são acessados quando a região é o tema tratado em alguns discursos. Walnice Galvão (2004, p. 375) afirma que, no Cinema Novo, filmes 
como Deus e o Diabo na Terra do Sol (1964), de Glauber Rocha, Vidas Secas (1963), de Nelson Pereira dos Santos, A Hora e a Vez de Augusto Matraga (1965), de Roberto Santos, entre outros, tiveram nos seus enredos, nas suas ambientações e na escolha de seus personagens, a direta influência dos conceitos regionalistas oriundos principalmente de obras literárias de Euclides da Cunha, José Lins do Rego, Graciliano Ramos e Guimarães Rosa. O fator que sinaliza o papel que tais autores desempenham na sustentação de arquétipos relacionados à região não é o pertencimento das obras a uma tendência literária que tem o regionalismo como parâmetro de produção, mas o recurso a determinados fenômenos, fatos e figuras dramáticas que adquirem status simbólico nessas narrativas.

Assim, beatos, cangaceiros e vaqueiros em meio a uma paisagem árida e hostil, coronéis e seus jagunços, retirantes e romeiros, sertão e litoral, fazem-se personagens e ambientes que preenchem o imaginário que permeia os significados de Nordeste. O questionamento que nos cabe diz respeito ao como e ao porquê da recorrência a tais elementos na produção fotográfica que, para tanto, busca, nas narrativas literárias, suas fontes. Logo, ao conjunto de influências dos quais o fotógrafo dispõe em seu processo de criação agrega-se um enredo finalizado, com personagens caracterizados e ambientes descritos.

O fotógrafo, então, se encontra imerso tanto no espaço criado pelo autor quanto no da realidade concreta. Seu desafio faz-se duplo, pois, se já buscava driblar as condições que a experiência da relação direta com o contexto traz, o estilo e as alusões do próprio escritor inscritas em sua ficção constituem novas dimensões da cultura com as quais ele tem que lidar. Dimensões oriundas de um tempo e de um espaço que não são os experimentados pelo fotógrafo, mas que nutrem proximidades com os mesmos; elas já foram disseminadas por meio do acesso às obras e, portanto, atenderam às expectativas de um ou de vários públicos que, considerando os significados culturais já assumidos por tais enredos, podem surgir diante do trabalho fotográfico. 


\section{Evandro Teixeira: um caminho pela fotografia}

"Minha aventura pessoal identifica-se com a aventura vivida pelo mundo. Não tenho méritos por isso. Sou um homem manejando uma câmera2". Com tais palavras, Evandro Teixeira se define no início do seu livro Fotojornalismo, de 1982. Este é um relato que significa não só a consciência que ele tem sobre o fazer fotográfico, mas conota a pluralidade presente em sua trajetória profissional. Evandro, apesar da modéstia, reconhece a importância dos trabalhos fotográficos que realizou para a compreensão de aspectos da história do Brasil e do mundo.

Nascido em 1935, o sertão baiano foi o ambiente no qual cresceu, ele relata que seu primeiro contato com a fotografia se deu "[...] ainda na infância com a produção de jornaizinhos na escola e em seguida um tablóide que circulava nas cidades de Jequié e Ipiaú"’. Estudou na Escola de Belas Artes no Rio de Janeiro, e, em 1958 começou a trabalhar no jornal Diário da Noite, de Assis Chateaubriand. Sobre o início de sua trajetória, relata que foi “[...] empurrado por um amigo que achava que eu devia sair da Bahia para fazer carreira no Rio [...] Cheguei na porta dos Diários Associados, onde encontrei um cabra da peste, bravo, de terno e gravata, que me fez um fotógrafo casamenteiro"4. A partir desta primeira experiência, o fotojornalismo foi o meio pelo qual Evandro Teixeira fez, do ofício fotográfico, sua profissão.

No ano de 1963, passou a integrar a equipe do Jornal do Brasil. A abrangência de diversos temas e fatos é própria do cotidiano do fotojornalista e, no caso da trajetória de Evandro, tal diversidade vai da cobertura de eventos esportivos ao acompanhamento do contexto político que envolveu o regime militar no Brasil, passando por episódios políticos

2 Depoimento de Evandro Teixeira no prefácio do livro Evandro Teixeira: fotojornalismo. Rio de Janeiro: JB, 1982.

3 Informações presentes em entrevista concedida a Célia Chaim, veiculada em J\&Cia, em 19 de outubro de 2009, p.2, disponível em http://www.jornalistasecia.com.br/especial.htm

4 Idem, Ibidem. 
nos países da América Latina e por flagrantes de situações do dia a dia. Além da sua atuação em um veículo de imprensa, o trabalho de Evandro Teixeira está exposto em museus e integra coleções nacionais e internacionais.

Independentemente dos temas que tratam, suas fotografias transmitem a atenção aos detalhes que denotam um individuo cuja sensibilidade se exacerba em cenas dramáticas e ao mesmo tempo poéticas. A escolha do momento e dos elementos em suas composições denota a acuidade que possui para articular construções cuja interpretação requer mais que uma rápida observação. Ele se vale do caráter polissêmico da imagem fotográfica tanto para promover um relato imagético de acontecimentos importantes do contexto histórico vivido e, assim, emocionar e fazer refletir acerca destes e de suas consequências, quanto para subverter o olhar dos mais desatentos, que enxergam, na imagem, apenas a dimensão plástica, ignorando as intencionalidades do seu realizador e o significado que elas assumem no meio cultural.

Em 1997, Evandro Teixeira iniciou um projeto fotográfico na região baiana onde Antônio Conselheiro e seus seguidores ergueram Canudos. No período de quatro anos, realizou visitas ao local, conviveu com seus moradores e conheceu os ambientes que compuseram a narrativa de Os Sertões, de Euclides da Cunha. Sobre a sua motivação para lançar-se neste projeto, ele ressalta, "Minha avó era dessa região e sempre contava histórias relacionadas ao grande conflito. Eu cresci ouvindo relatos sobre Canudos. Tempos depois, li Os Sertões, e algo muito forte ficou marcado em minha memória 5 ". Esta iniciativa deu origem a um livro intitulado Canudos - 100Anos e, a partir dessa publicação, podemos intuir o interesse de Evandro Teixeira pelo trinômio Fotografia-Nordeste-Literatura.

Na década seguinte, realizou um ensaio para ser publicado junto a uma reedição de Vidas Secas, de Graciliano Ramos ${ }^{6}$. Com fotografias feitas em Alagoas e em Pernambuco, Evandro Teixeira teve, na obra

5 Relato presente em CORREIA FILHO, João. Entre letra e luz. Revista da Cultura. $20^{\circ}$ Ed. Março de 2009.

6 Evandro Teixeira foi convidado pela editora Record a participar de uma reedição especial de Vidas Secas em homenagem a Graciliano Ramos no ano de 2008. 
literária, uma forma de guia para a eleição dos personagens e dos ambientes que são representados nas imagens. Não se trata de um trabalho de ilustração do texto do escritor alagoano, mas de um processo de cruzamento de referências, que ora são justapostas, ora se sobrepõem. O fotógrafo ressignifica cenas emblemáticas da trajetória de Fabiano, Sinhá Vitória, seus dois filhos e a cadela baleia: a partir do seu próprio modo de ver, ele aponta seus conhecimentos prévios, tanto sobre obra quanto acerca do contexto ao qual ela pertencia e sobre os desdobramentos que teve contribuíram na concepção do ensaio. Em suas palavras,

Graciliano Ramos, o 'Vidas Secas' no filme, o 'Vidas Secas' no livro, que eu conhecia, que eu li, reli, pra fazer a obra e essa minha vivência pelo sertão, então, essa é uma coisa familiar, é uma vivência minha pelo Nordeste, pelo Brasil. E, você viver, conviver, três meses com aquela gente do nosso sertão, do nosso Brasil, é, novamente, [...] uma história de vida. ${ }^{7}$ (TEIXEIRA, 2011, s/n)

Na busca por construções imagéticas, as quais abordam o ambiente compreendido como nordestino reside uma maneira de Evandro imprimir elementos biográficos de forma mais direta em seu discurso fotográfico. Os relatos e as paisagens que povoam suas lembranças da infância ganham ênfase na concepção de uma obra que transita entre o espaço da sua memória, aquele no qual se encontra no instante do clique e aquele constituído pelo escritor na obra que lhe serve de inspiração

\section{Entre imagens: uma certa representação do Nordeste}

No conjunto de fotografias que compõem o ensaio Vidas Secas, de Evandro Teixeira, de imediato, percebemos a intenção em se estabelecer coesão entre as imagens. Cada uma faz-se capaz de representar aspectos

7 Relato presente em entrevista que nos foi concedida por Evandro Teixeira, em 13 de dezembro de 2011. 
distintos do contexto fotografado, porém, vistas em sequência, a mensagem sustenta-se sem a obrigatoriedade da recorrência às anteriores ou às subsequentes, pois há um fio condutor sobre o qual estão dispostas, instaurando uma ligação entre elas.

Se o ambiente fotografado denota as consequências da seca, ou, se as situações cotidianas representadas estabelecem contrastes com os padrões de vida predominantes em outros espaços, tais opções distanciamse de uma formatação com viés político panfletário, o que condiz com a postura do escritor Graciliano Ramos na elaboração de Vidas Secas. Predominam a investigação psicológica e a ênfase no que cada situação representada tem a dizer além do seu significado estereotipado.

Deste modo, a intenção de Evandro não é fazer um apelo para que os olhos se voltem para a região, seu intuito é o de expressar a experiência estética e cultural em um espaço que ele já conhece. Há um Nordeste, para o fotógrafo, que independe de relatos da historiografia oficial e da mídia; é aquele forjado a partir das vivências de sua infância, das estórias ouvidas e repetidas, das observações acessadas na memória quando essas referências precisam fazer-se presentes. E, há outro Nordeste: um que tem, nos discursos históricos, literários e midiáticos, um dos pontos de apoio para que a relação entre fotógrafo e ambiente se estabeleça.

Segundo Evandro Teixeira, na etapa de concepção do trabalho que antecedeu a feitura das fotografias, a releitura da obra fez parte do seu processo de criação,

[...] para fotografar Graciliano Ramos, eu li, eu já tinha lido Vidas Secas [...] Então, é importante que você conheça a história daquele seu personagem, daquela gente que você vai fotografar [...] Eu saio do Rio de Janeiro sabendo que eu vou fazer um trabalho sobre Graciliano Ramos e eu sei que vou encontrar aquela minha gente, aquela gente do Nordeste, aquela gente sofrida, aquela gente que compôs a história e o olhar do Graciliano Ramos. Então, isso em nada é difícil pra mim ${ }^{8}$. (TEIXEIRA, 2008).

8 Relato presente em entrevista ao autor por Evandro Teixeira. 
Assim, tais imagens remetem ao anseio de uma representação imagética que traga, à tona, aqueles que poderiam vestir as figuras criadas por Graciliano Ramos no enredo de Vidas Secas, sem que, no entanto, o espaço e o tempo nos quais elas se encontrem sejam uma condição determinante para o seu reconhecimento. São incontáveis "Fabianos" os que cruzaram o caminho do fotógrafo ou que foram buscados, e o que eles têm a acrescentar para a narrativa sobre o Nordeste fez-se o fator a ser explorado por Evandro Teixeira.

Tendo quatro imagens como mostra do trabalho que estamos estudando, a nossa análise dá atenção ao papel de mediador da realidade assumido pelo indivíduo que protagoniza o fazer fotográfico. A visualidade sobre a região Nordeste, viabilizada pelas construções de sentido expressas nas fotografias, faz-se um modo de ver particular, individualizado, que emerge como um relato do fotógrafo sobre as experiências que envolveram a realização das imagens. A seguir, tendo como referência as questões que colocamos anteriormente e reconhecendo as particularidades aqui presentes, seja no perfil do autor, ou, no diálogo deste com o relato literário, analisaremos algumas imagens do ensaio, buscando melhor compreensão deste processo específico.

Figura 1 (TEIXEIRA, 2008, p. 26).

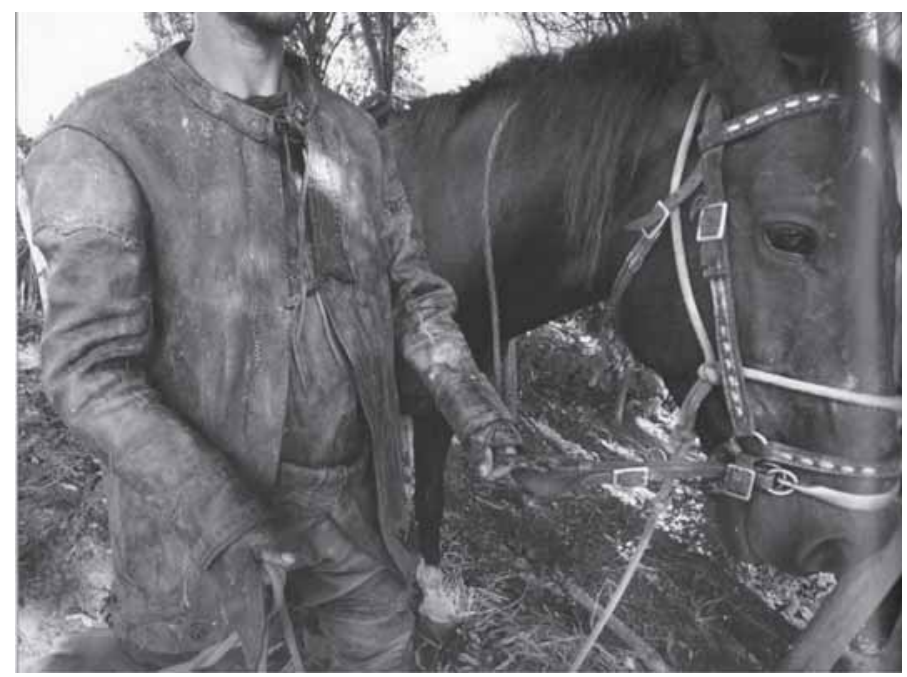


A abordagem de Evandro Teixeira firma-se na relação indivíduoambiente neste ensaio. A Figura 1 abriga uma das características que podemos atribuir a este trabalho: a constituição de uma paisagem humanizada acerca do espaço do Nordeste. Homens e mulheres não surgem como pessoas que estão à mercê da paisagem, eles a compõem e a modificam construindo seus próprios significados e valores a partir de sua intervenção. Nesse sentido, o enquadramento escolhido pelo fotógrafo instrumentaliza os elementos representados. O uso do animal para enfrentar o espaço e a roupa de couro são vias criadas pelo sertanejo para lidar com o ambiente, para sobrepor-se a ele. Nesta fotografia eles assumem o valor dos objetos que servem aos anseios do indivíduo antes de serem indumentária e forma de locomoção típicas do Nordeste.

Figura 2 (TEIXEIRA, 2008, p. 109).

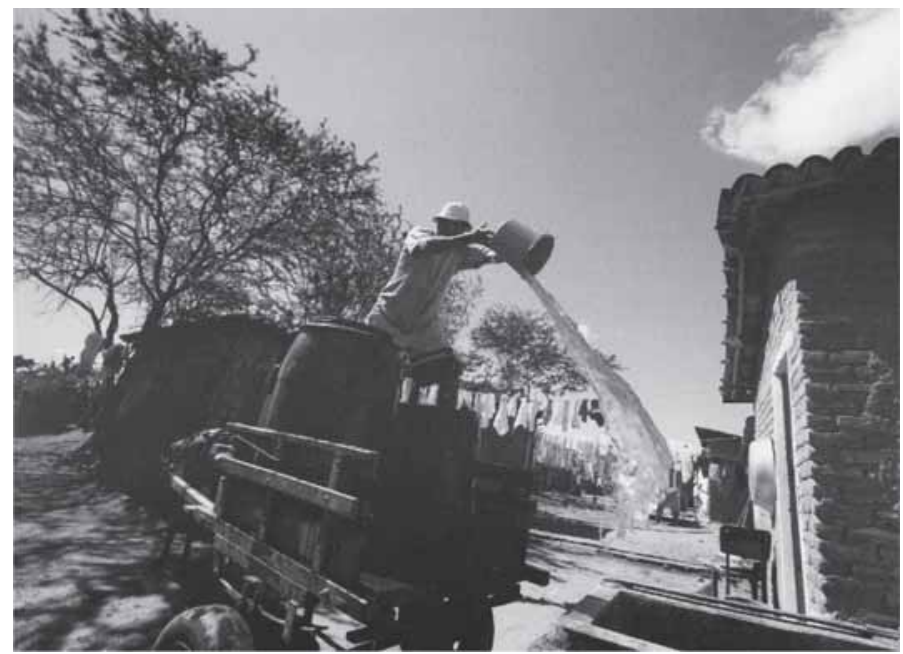

As opções de enquadramento e de ajuste da câmera usadas enfatizam a dramaticidade na Figura 2. A escolha do contraluz colaborou para que o gesto do homem ganhasse destaque diante dos detalhes do ambiente que o circunda. Observamos que a velocidade do obturador escolhida permitiu a elaboração de uma ênfase à relação do sertanejo com a água. Nos termos de Guran, 
Os procedimentos relativos ao enquadramento e à escolha do instante são ligados às questões técnicas (iluminação, objetivas, diafragma, foco, tipo de filme), mas eles dependem também e, sobretudo da própria postura do fotógrafo face ao seu objeto de estudo (GURAN, 2000, p. 9).

A abordagem trazida pelo fotógrafo busca demonstrar que abastecer os reservatórios de água da casa está entre as atividades corriqueiras dessas pessoas, sua construção imagética a iguala a outros afazeres como costurar, ir à feira ou cozinhar, práticas que surgem ao longo do ensaio. São situações cotidianas que tecem as vivências da população, tarefas que se inserem no dia-a-dia de outros espaços. No entanto, Evandro Teixeira tem conhecimento dos aspectos que as singularizam, que as relacionam com características definidoras da cultura do ambiente tratado; neste caso, o tipo de meio de transporte, os recipientes usados, o ritual que envolve coleta e distribuição da água, detalhes que, uma vez identificados, permitem construções que aprofundam os saberes sobre a realidade abordada e expressam a familiaridade com a qual tal espaço é esteticamente experimentado. O fotógrafo vale-se disso para vincular sua representação fotográfica ao universo discursivo que envolve a concepção de Nordeste.

Figura 3 (TEIXEIRA, 2008, p. 157).

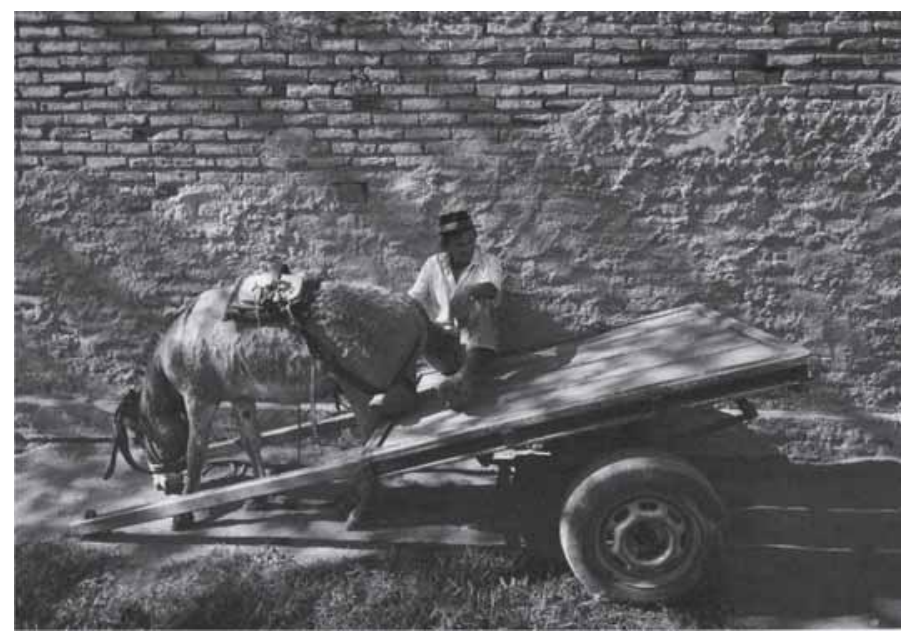


Na Figura 3, os efeitos de contraste e o explorar da oscilação entre luz e sombra conduzem a uma representação que remete ao sentido de simplicidade, de singeleza de sua narrativa imagética. A sombra que cobre o rosto do homem surge como uma opção que denota o anseio de enfatizar a situação como um todo, considerando cada elemento que a compõe; carroça, animal, e textura da parede são informações que se somam ao personagem. A fotografia não se configura como um flagrante banal ou como uma imagem pautada em investigações estéticas ousadas. É uma cena entre inúmeras que se fazem diante do fotógrafo, ele a elege e a partir de sua observação e sensibilidade a transforma, a individualiza. Evandro traz à tona minúcias do espaço, para que as outras faces da cultura se revelem, ou, sejam, pelo menos, mencionadas.

Figura 4 (TEIXEIRA, 2008, p. 184).

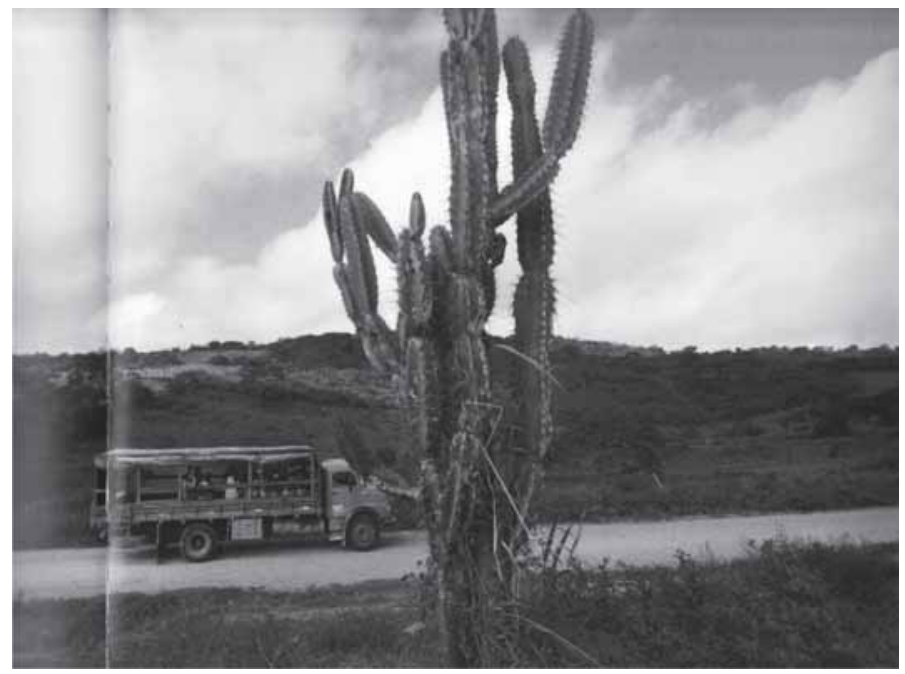

Na Figura 4, a composição faz uma referência à fuga da população diante dos problemas enfrentados no ambiente em que vivem. A submissão à mobilidade é um tema tratado por Graciliano Ramos como o ponto sobre o qual o caráter cíclico da vida do sertanejo se firma, seu enredo começa e termina em tentativas de melhoria a partir de deslocamentos 
espaciais. Pela forma como Evandro dispõe os elementos nesta imagem, podemos perceber uma espécie de relação causa-consequência entre eles, como se um implicasse o outro. Ao mesmo tempo em que a planta dotada de espinhos no primeiro plano remete à situação da qual as pessoas desejam fugir, ao caminhão atribui-se o valor do meio encontrado para que tais anseios sejam alcançados. O amplo ângulo de visão permite que a estrada e o espaço descampado que a circunda sejam percebidos, eles contribuem para a construção de uma atmosfera de isolamento para a realidade representada.

\section{Considerações finais}

As formas de se conceber e narrar o Nordeste se tocam em vários pontos. Representá-lo, muitas vezes, é algo mais enfatizado que definilo sobre um conceito fixo. Há um fluxo de ideias e ideais que aparentemente vão no mesmo sentido, porém, quando observados com maior proximidade permitem que sejam reconhecidas suas peculiaridades, e, até mesmo, as divergências que possuem entre si. Ao envolver-se com uma proposta de representar o Nordeste, incluindo em suas referências a ótica literária, o modo de ver de alguém que optou pelos efeitos da palavra escrita para canalizar suas percepções, o fotógrafo está optando um universo de significados já constituído, publicizado e culturalmente reconhecido. Isso não significa que este será o único a ser acessado na concepção das imagens, nem implica em uma obrigatoriedade de instituição de referências.

A abordagem de Evandro Teixeira é alicerçada, em primeiro lugar, nas referências às suas próprias experiências enquanto alguém que pretende ser reconhecido como nordestino. Assumir-se como indivíduo que pertence ao contexto fotografado é a via encontrada para dar vazão à familiaridade que ele tem o intuito de expressar nas fotografias. A segunda característica é a elaboração de uma forma de conduzir o ensaio que remete ao percurso 
traçado pelos personagens de Graciliano Ramos, lançando mão do caráter cíclico dos acontecimentos com os quais eles lidam (seca, fuga, chuva e seca novamente) para costurar sua trama fotográfica, valendo-se de situações com as quais o ambiente já está relacionado para compor uma visualidade intimista e reveladora do dia-a-dia da população sertaneja.

O diálogo com a literatura faz-se uma opção que remete à consideração da importância que determinados relatos adquiriram ao longo da história, além de dar ao fotógrafo o desafio de arquitetar representações que possam, de alguma maneira, estabelecer relação com a obra e com o seu contexto, evidenciando, a partir das fotografias, o olhar particular e a sensibilidade de quem as realizou. A partir dessa perspectiva, percebemos que tal abordagem é passível de mais questionamentos e traz a possibilidade de discussões que vislumbrem este e outros trabalhos que dialoguem com o trinômio fotografia-Nordeste-literatura. Assim, as ideias aqui explicitadas representam alguns aspectos de nossas inquietações, que, ao longo da pesquisa podem esclarecer-se ou fazerem surgir outras.

\section{Referências}

\section{ALBUQUERQUE JUNIOR, Durval Muniz de. A invenção do}

Nordeste e outras artes. - 3. ed - Recife:Ed. Massangana; São Paulo: Cortez, 2006.

CORREIA FILHO, João. Entre letra e luz. Revista da Cultura. $20^{\circ}$ Ed. Seção Reportagem, p. 22-26. Março de 2009. Disponível em: http://www.revistadacultura.com.br:8090/revista/rc20/ index2.asp?page=reportagem. Acesso em 03 de fev. 2012.

CARVALHO, Ricardo E. Ismael de. A invenção do Nordeste na obra de Gilberto Freyre e de Celso Furtado. In: Anais do XII Encontro Regional de História - ANPUH. Rio de Janeiro, 2006. 
FLUSSER, Vilém. Filosofia da caixa preta: Ensaios para uma futura filosofia da fotografia. São Paulo: Ed. Hucitec, 1985.

GALVÃO, Walnice Nogueira. 'Metamorfoses do sertão'. In: Estudos Avançados. n. 18 (52). São Paulo, 2004.

GURAN, Milton. Fotografar para descobrir, fotografar para contar. In: Cadernos de Antropologia e Imagem, Vol. 10, n. 1. Rio de Janeiro: UERJ, 2000.

KOSSOY, Boris. Realidades e ficções na trama fotográfica. São Paulo: Ateliê Editorial, 1999.

TEIXEIRA, Evandro. Evandro Teixeira: fotojornalismo. Textos de Carlos Drummond de Andrade, Marcos Sá Correa, Antonio Callado e Otto Lara Rezende. 2. ed. Rio de Janeiro: JB, 1982.

. Vidas secas: 70 anos, Graciliano Ramos. Rio de Janeiro: Record, 2008.

\section{. O fotógrafo arretado que o Brasil e o mundo aprenderam}

a admirar. Entrevista concedida a Célia Chaim em outubro de 2009. Disponível em: http://www.jornalistasecia.com.br/especial.htm. Acesso em: 20 jan. 2012.

SILVEIRA, Rosa Maria Godoy. Regionalismo: a formação do conceito de nordeste. VI Encontro Anual da ANPOCS, Nova Friburgo, RJ, 1982. In: CARVALHO, Ricardo E. Ismael de. A invenção do Nordeste na obra de Gilberto Freyre e de Celso Furtado. In: Anais do XII Encontro Regional de História - ANPUH. Rio de Janeiro, 2006. 